\title{
A formação do indivíduo nas relações sociais: Contribuições teóricas de Lev Vigotski e Pierre Janet
}

\author{
Maria Cecília Rafael de Góes*
}

\begin{abstract}
RESUMO: Este trabalho examina o Manuscrito "Psicologia Humana Concreta", de Lev Vigotski, com o propósito de assinalar o vigor dos argumentos do autor sobre o papel fundante das relações sociais na formação do indivíduo. O foco é posto nas passagens do texto que são mais pertinentes à construção recíproca do "eu" e do "outro". Na abordagem desse tema, são exploradas algumas proposições de Pierre Janet, já que ele é uma das importantes referências que Vigotski inclui no Manuscrito. Em seguida, as contribuições desses teóricos são ilustradas através de análises de um estudo de elaborações sobre o eu e o outro, no jogo imaginário em crianças. Finalmente, são destacadas as perspectivas profícuas que o Manuscrito oferece para a investigação atual, bem como as complexas questões que ele deixa em aberto.
\end{abstract}

Palavras-chave: Relações sociais, relação eu-outro, Vigotski, Pierre Janet

O texto "Psicologia Humana Concreta" (1989) ${ }^{1}$, de Lev Vigotski, contém várias passagens compostas de idéias apenas esboçadas e fragmentos de proposições. Por ter as características de "anotações para si", esse "Manuscrito", deixa o leitor, em diversos momentos, frente a dificuldades de interpretação das afirmações incompletas e dos argumentos abreviados ou truncados. Entretanto, dada a densidade das questões abordadas, ele oferece muitas possibilidades de leitura e contém uma riqueza teórica que convida à exploração de variados temas, expostos ou implícitos. $\mathrm{Na}$

* Professora da Universidade Metodista de Piracicaba, Faculdade de Educação - PPGE/ Unimep. E-mail: mcrgoes@iepmail.unimep.br 
presente discussão, pretendo reportar-me à proposição geral que aparece com grande visibilidade e recorrência no "Manuscrito", certamente por ser uma das teses centrais de toda a obra desse teórico - a proposição sobre o papel fundante das relações sociais na formação do indivíduo. Meu propósito é focalizar aspectos dessa tese e assinalar a força dos argumentos sobre as relações "eu-outro". Para apoiar essa leitura do "Manuscrito", estabeleço alguns vínculos com discussões teóricas de Pierre Janet (1859-1947), autor que é referência para Vigotski nesse e em outros textos. Após uma retomada sucinta dos dois teóricos, busco ressaltar perspectivas promissoras e possibilidades interpretativas deriváveis de seus trabalhos. A esse respeito, tomo como ilustração alguns apontamentos de um estudo que estou realizando sobre o jogo imaginário em crianças. $\mathrm{Na}$ parte final, considero, sucintamente, as elaborações consistentes e os problemas suspensos que compõem o esforço teórico de Vigotski no que concerne às questões focalizadas.

\section{Individuação, sociogênese e a relação eu-outro}

Ao discutir sobre a formação do indivíduo, Janet $(1929)^{3}$ focaliza as transformações na infância e na idade adulta, mas ressalta a importância de considerarmos os indicadores da história social (dos acontecimentos dos séculos e das populações) e da evolução da espécie. De forma consonante a essa perspectiva, suas formulações sobre a ontogênese privilegiam a dimensão social dos processos humanos. Quanto à relação individual-social, as análises que interessam são especialmente aquelas que se reportam à formação da personalidade e à individuação, que se entrelaçam nas elaborações do autor.

Para Janet, na origem da vida, estabelece-se a percepção do corpo próprio, enquanto algo separado dos objetos e enquanto um corpo que existe entre outros corpos viventes. A partir dessa percepção, constrói-se o mim e se desdobra a formação do indivíduo. Esses processos ocorrem no encontro com outros homens, e, por isso, "o mim, é uma invenção da humanidade (...) a humanidade criou o indivíduo" (Janet 1929, p. 422). Pode-se falar de uma inter-relação da personalidade corporal, portanto, que se distingue do mundo, e da personalidade social, que se constitui nas relações com o grupo. Um outro ângulo de consideração da personalidade aponta para seu caráter temporal, pois ela se transforma e se organiza ao longo da vida. 
Focalizando a idéia de personalidade, Janet aborda as concepções que admitem uma unidade e uma identidade do ser, alertando para o equívoco e a ilusão dessas concepções. Erroneamente supõe-se uma unidade, que seria essencial e apreendida pelos sentidos, e uma identidade, a qual corresponderia, por sua vez, a uma unidade preservada no curso do tempo, frente à multiplicidade dos acontecimentos. O autor contra-argumenta que a personalidade encontra-se em constante mudança e se apresenta com faces múltiplas. O próprio mundo no qual o indivíduo atua é múltiplo. Além disso, a personalidade se faz pela sociedade, ou na vida social, em um processo que implica também o trabalho interno do ser humano para se unificar aos outros e deles se distinguir, assumindo papéis mais ou menos diversos daqueles desempenhados pelos demais membros do grupo. "O indivíduo psicológico é uma criação particularmente social. Nós nos inventamos graças à sociedade que nos fez e que pode igualmente nos desfazer" (Janet 1929, p. 266).

Nas relações do indivíduo com o grupo social, a linguagem é fundamental. A palavra veio, num nível mais geral, a caracterizar a condição humana. Em termos mais específicos, na ontogênese, a linguagem tem a função de regular as ações e de propiciar a conduta intencional humana. Através da linguagem, o indivíduo prepara um ato a ser consumado. Como exemplo, na elaboração das pinturas rupestres, há uma "representação verbal, imaginada", que antecede ao que é executado na parede da gruta. Embora, em algumas análises, a linguagem seja definida por Janet como função representativa, ele atribui a ela, ao mesmo tempo, um estatuto mais forte, ao afirmar sua distintividade frente a outras ações e ao destacar sua participação nas relações sociais ou no planejamento das ações individuais.

Outro fundamento das relações do indivíduo com os outros está nos atos de comando e obediência, termos que não devem ser tomados em um sentido estrito, pois compõem uma concepção abrangente dos movimentos pelos quais os membros de um grupo social afetam-se mutuamente. O grupo social abrange outros que são os amigos, os inimigos, os associados etc., enquanto figuras específicas, mas é preciso considerar também os outros como "uma personalidade em geral", da humanidade. Eles sempre acompanham o indivíduo. Por isso, mesmo quando se está só, afastado e isolado dos outros, "carrega-se qualquer coisa do grupo, o pensamento desse grupo" (Janet 1929, p. 262).

Em um texto posterior (Janet 1936), o autor retoma e aprofunda aspectos dessas discussões. Problematiza a definição de indivíduo como 
unidade, reportando-se à lenda de Salomão e compondo um discurso de suposta réplica da verdadeira mãe ao rei. Resumindo as palavras de Janet, ela teria dito que, se um indivíduo for dividido ao meio, ele não se transforma em dois, mas é simplesmente suprimido. De acordo com Janet, a mulher superpõe, confunde (como se faz freqüentemente) duas idéias, a de unidade e a de indivíduo.

Essa fala hipotética é tomada como ponto de partida para a crítica à suposição da individualidade como unidade e propriedade absoluta de um ser particular. $O$ indivíduo não pode ser conceitualizado como uno. Ademais, muitas vezes ele próprio se sente dividido, hesitante: pode nutrir desejos e idéias morais opostas, pode apresentar uma multiplicidade de percepções sobre si... Por outro lado, apesar de não ser uma característica fundamental do ser humano, a idéia de unidade é naturalmente forte, porque é um modelo em direção ao qual a pessoa se orienta. Se a noção de indivíduo está ligada de alguma forma à divisão, não é por corresponder a uma unidade, mas por corresponder ao limite da possibilidade de divisão daquilo de que necessariamente faz parte - do grupo social. "A noção de indivíduo depende da noção de grupo humano, não há homem indivíduo se não há grupo de homens" (Janet 1936, p. 68). Assim, somente nesse aspecto dos argumentos o autor considera o sentido de não-divisão que o termo usualmente carrega, até por sua etimologia.

Dentro de sua visão sociogenética, Janet invoca a noção de socius (já esboçada por J. M. Baldwin), numa idéia aproximada de participante social da vida individual. Nos argumentos sobre individuação, as referências ao mim e ao eu alternam-se com invocações ao socius, ao outro e aos outros. Reitera a idéia de personalidade como uma obra social, lembrando ser ela uma construção que acontece articulada à construção das personalidades com as quais o indivíduo interage. Ao longo da vida, há uma repercussão recíproca entre as personalidades do indivíduo e dos outros. A singularização vem das experiências no grupo social. A separação do individual e a distinção entre pessoas são primeiramente realizadas no plano social e, depois, reconstruídas pelo próprio indivíduo. E, por isso, há uma base genética social para tudo aquilo em que um ser se torna - ele aplicará a si o que vivenciou com os outros.

As relações sociais, que fundam os processos individuais, são caracterizadas por tensões e equilíbrios. Estão vinculadas tanto à solidariedade quanto à coação. O homem constrói sua individualidade de forma contraditória, pois, ao se singularizar, ele é apoiado e constrangido. É sin- 
gularizado pelo nome que recebe, pelo ato de saudação do outro, pelos papéis atribuídos e expectativas postas. Sobre isso, diz Janet (1936):

Os homens em meio aos quais vivemos nos dão uma certa função social e nos forçam a preenchê-la. Eles nos atribuem um caráter particular e freqüentemente nos educam para que conservemos esse caráter. Enfim e sobretudo, eles nos dão um nome único, nos coagem a conservá-lo, a nos distinguir de outros homens que têm outros nomes (p. 56).

Reportando-se, novamente em 1936, aos atos de comando e obediência, Janet afirma que eles estão presentes nas várias formas de relações sociais, uma das quais é a imitação. Como parte essencial da formação da individualidade, a imitação abrange vínculos mútuos entre o indivíduo e os modelos sociais. Essa interpretação é interessante por mostrar que não existem processos sociais em que somente um lado é ativo. Para Janet (1936), a imitação não diz respeito apenas àquele que imita, como usualmente se acredita, mas também àquele "que se deixa imitar, que não se desgosta quando se copia seus movimentos, quando se o segue; que, ao contrário, coloca-se em evidência e faz movimentos bem visíveis que os outros possam facilmente imitar" (p. 103). Comando e obediência vinculam-se também e principalmente à linguagem. Nesse âmbito, comandar e obedecer correspondem a "dois atos inseparáveis, 0 ato de falar e o ato de ser falado" (Janet 1936, p. 116). Aqui se destaca o papel regulador da linguagem, que deve ser entendido como de inter-regulação, sob uma concepção de um tenso entrelaçamento de condições de subordinação e de partilha, de se sujeitar e se impor, no encontro do indivíduo com outros.

Vários aspectos dessas proposições aparecem em formulações semelhantes, no "Manuscrito" de Vigotski e em trabalhos posteriores (por exemplo, Vygotsky 1981 e 1987a).

No "Manuscrito", o autor argumenta que a perspectiva sociogenética é o caminho para a compreensão do funcionamento superior, das formas de ação especificamente humanas. Refere-se ao socius (conforme conceito de Janet), enfatizando que os outros do grupo social são participantes necessários da formação do indivíduo. Isso porque as relações sociais estão na gênese de todas as funções individuais; essas originam-se das formas de vida coletiva, dos acontecimentos reais entre 
pessoas. Dessa perspectiva, o desenvolvimento é visto como cultural, como um curso de transformações que ocorrem orientadas, antes, para o outro e, então, para si.

A noção de indivíduo não pode estar ligada à de uma personalidade com características estáveis ou uniformes, que desempenha um "papel fixo". Os papéis são variados e, portanto, o singular, construído ao longo do desenvolvimento, está entrelaçado com o heterogêneo, no que diz respeito tanto à personalidade quanto às funções psicológicas individuais. Adicionalmente, o indivíduo deve ser visto como algo em construção e não como estrutura natural. Por um lado, trata-se de algo em processo (individuação), que não pode ser concebido ou investigado como uma cena estacionária; por outro lado, é um processo que depende das relações sociais, que é marcado pelo papel fundamental do socius.

A linguagem tem alguns destaques importantes no "Manuscrito", embora, a meu ver, sua posição de centralidade na constituição dos processos humanos esteja menos enfatizada do que em textos posteriores do autor. Mas é atribuído um papel fundamental à palavra e à interação verbal. A palavra tem o poder de regular e de conferir um caráter mediador à relação entre as pessoas. As interações verbais internalizam-se, isto é, são reconstruídas no plano individual, transformando-se em funções psicológicas e criando a base para a estrutura social da personalidade. As funções psicológicas emergem no plano das relações sociais, e o indivíduo se constrói a partir delas. Nesse sentido, Vigotski afirma que "nos tornamos nós mesmos através dos outros" (p. 56) e que "eu sou uma relação social de mim comigo mesmo" (p. 67).

Em suma, essas idéias de Janet e de Vigotski mostram que a construção social do indivíduo é uma história de relações com outros, através da linguagem, e de transformações do funcionamento psicológico constituídas pelas interações face-a-face e por relações sociais mais amplas (que configuram lugares sociais, formas de inserção em esferas da cultura, papéis a serem assumidos etc.).

Quanto ao "Manuscrito", especificamente, entendo que o valor da sua leitura (por certo, com variadas possibilidades de interpretação) em três diferentes âmbitos: marca o que, na atualidade, ainda permanece como referencial de sustentação conceitual e metodológica para a perspectiva histórico-cultural; compõe-se de questões provocativas, que devem ser adensadas, a partir das proposições sobre a constituição social 
do indivíduo, e, finalmente, deixa expostas ou entrevistas lacunas que mostram a necessidade de aprofundamentos e expansões teóricas (em especial, no que se refere às noções de indivíduo-socius e eu-outro $)^{4}$.

Com a intenção de ilustrar as possibilidades interpretativas e as indagações que a linha de argumentação do "Manuscrito" pode trazer, passo a apresentar explorações iniciais de uma pesquisa sobre os modos de experimentação "de ser o eu e de ser o outro", que a criança vivencia nos acontecimentos do jogo imaginário (no sentido de jogo de imaginação, caracterizado por ações de "faz-de-conta" e pela assunção de papéis) ${ }^{5}$.

\section{Indícios da construção do eu e do outro: A criança no jogo imaginário}

Vigotski abordou o brincar na infância e os processos de imaginação, principalmente nos textos "O papel da brincadeira no desenvolvimento" e "Arte e imaginação na infância" (Vygotsky 1984 e 1987b, respectivamente). Argumentou que, embora com pesos diferentes, tanto o desprendimento propiciado pela imaginação quanto a subordinação às regras estão presentes nas várias formas do brincar. No caso do jogo de faz-de-conta, que se constitui como situação imaginária, ocorre uma libertação do perceptual-imediato ao mesmo tempo em que as regras da realidade se impõem de forma marcante.

De suas discussões, pode-se derivar a idéia de que esse tipo de brincadeira tem sua gênese naquilo que é vivenciado e conhecido, embora a atividade imaginativa envolvida não seja apenas recordar, mas reelaborar experiências, combinando e criando novas realidades, de acordo com necessidades e preferências. Porém, mesmo inovando, a criança leva em conta as regras, em termos do que é pertinente a um papel social, do que é apropriado ao agir com as coisas e de como os acontecimentos podem se organizar. Assim, no espaço das ações lúdicas, a criança re-cria suas vivências cotidianas, reproduz modos culturais de ação com ou sobre objetos e modos de relação interpessoal.

Vigotski (1984) menciona, embora sem muita explicitação, a questão do "eu fictício" que se apresenta nas brincadeiras, quando ele comenta, por exemplo, a situação em que uma irmã brinca "de irmã" com a outra. Por estar envolvida com o plano imaginário, a atividade propicia à criança começar a compreender, a reconhecer o "ser irmã" ou aquilo que carac- 
teriza a relação enquanto irmã, que é distinta de outras relações. Ao assumir variados "eus fictícios", com personagens e papéis implicados, ela recria tipos de relação, que se distinguem pelas regras de comportamento em cada caso.

No que concerne à relação eu-outro, parece-me interessante considerar o envolvimento da criança com esses "eus" fictícios e atentar para as diferentes formas pelas quais ela invoca e recria os outros na brincadeira.

Ao assumir um "eu" fictício, a criança efetua, no plano imaginário, experimentações do lugar dos outros, o que contribui para que ela vá construindo seu eu nesse processo. Os papéis assumidos constituem diferentes "eus" fictícios, nas experimentações de ser o "outro". São vivências "do eu do outro", para usar a expressão de Bakhtin (1997).

O jogo imaginário é, portanto, uma instância em que a criança maneja, por assim dizer, imagens de si e de outros membros da cultura. Nesse processo, a relação eu-outro refina-se. Isso se dá não apenas porque as crianças aprendem a negociar com parceiros (os outros presentes) e com eles compor a orquestração das ações da "história", conforme é freqüentemente lembrado nas análises do brincar. É igualmente ou mais significativo o fato de que existem os personagens encenados e imaginados, com seus papéis correspondentes.

$\mathrm{Na}$ observação de situações imaginárias criadas, chama a atenção o fato de que, na encenação dos acontecimentos derivados do cotidiano, expandem-se, para a criança, as possiblidades de se deslocar de um papel para outro, de transitar por temas e tramas diversas. Ela brinca daquilo que já vivencia (filha); daquilo que ainda não pode ser (mãe, médica, professora); daquilo que o código social censura (ladrão, bêbado, seqüestrador); daquilo que aspira ser (pai, mecânico, astronauta); e assim por diante.

Ao se envolver com tantos personagens, a criança pode criar seqüências que contêm cenários representados (atuando com apoio nos objetos disponíveis e nas relações com parceiros presentes) e também cenários conjeturais (reportando-se a situações e personagens não encarnados em suportes tangíveis, mas presumidos principalmente pelos enunciados dos participantes). Ao experimentar ser o eu e ser o outro, a criança re-produz modelos sociais e rituais de vários espaços da cultura, experiências que propiciam a ela singularizar-se e construir seu eu. Trata-se de um eu com múltiplas faces, impregnado que está da dinamicidade vinculada aos vários personagens e seus papéis. 
Além da multiplicidade dos "eus fictícios" assumidos, há que se considerar a diversidade de formas de ocupação do lugar do outro que se constata no brincar. Numa análise global das situações de jogo imaginário, podem ser salientadas duas grandes modalidades de personagens os incorporados e os projetados, com suas peculiaridades nos modos de agir e enunciar. No primeiro caso, a criança "é" o outro, incorpora-o, fala e age de acordo com o papel correspondente; no segundo, a criança constrói o outro, projetando-o num objeto, sobre o qual age e fala.

O exemplo a seguir mostra uma brincadeira com personagens incorporados. (Esse e os próximos exemplos são de crianças de uma instituição de educação infantil, em atividade numa brinquedoteca. Nas descrições, "T" refere-se a Turno, e as falas estão reproduzidas em itálico.)

Tina e Carla estão no canto do toucador e começam uma brincadeira. Tina é mamãe de uma boneca e Carla é a babá. Carla pega um celular que, ao apertar alguns botões, imita o som de chamada.

T1. Carla - Alô! Ah, a Tina? Pera um pouquinho que ela quer falar com você.

Tina pega o telefone

T2. Tina - Alô! Seu vagabundo! Ce não serve pra nada. E você vai lá com aquela sua namorada, aquela sem vergonha!

Desliga e deixa o celular de lado. Carla faz o barulho do celular tocando de novo e atende. Dirige-se a Tina.

T3. Carla - É ele de novo. Quer falar com você.

Tina atende o telefone.

T4. Tina - Oh, sai daqui! Você vai morar na rua, viu? Vou dar um tapão na sua cara, seu sem vergonha.

Tina desliga o celular. Dirige-se à colega.

T5. Tina - Se tocar esse telefone de novo, eu vou jogar no lixo.

T6. Carla - Ai, meu Deus...

Carla faz o telefone tocar novamente. Tina levanta, expressando raiva. Pega o telefone, como se jogasse fora, colocando-o em cima de uma mesa longe do toucador.

A monitora, que estava observando, dirige-se a Tina.

T7. Monitora - Nossa, mas que brava que você é! Você jogou o telefone fora, mas por que? 
T8. Tina - Porque ele ligou de novo.

Carla pega o telefone, e Tina mostra-se irritada.

T9. Tina - Joga esse telefone fora!

T10. Carla - Eu vou sair e vou levar ele (referindo-se ao telefone).

Tina fica se enfeitando no toucador, com brincos e colares. Carla afastase, passeando com a boneca no carrinho de compras. Passa-se algum tempo, Carla ativa o telefone de novo.

T11. Carla - Dá aqui que eu atendo.

T12. Tina - Não. Dá aqui. (Pegando o telefone) Moleque, você é sem vergonha e eu vou jogar o telefone no lixo.

T13. Monitora - Mas você vai jogar outro telefone no lixo, Tina?

T.14 Tina - Vou!

T15. Monitora - Mas o telefone não tem culpa.

T16. Tina - Tem sim! Se ele vier, eu vou dar um tapão na cara dele.

T17. Monitora - Mas se você conversasse com ele, não era melhor do que ir batendo? Conversa com ele primeiro.

T18. Tina - Eu vou levar a nenê, não quero nem saber se ela vai chorar. Vou dar um tapão na cara dele. Eu não quero nem saber.

(As meninas se deslocam pela sala e envolvem-se em outras atividades.)

Tina e Carla são colegas, mantêm entre si um certo tipo de relação, mas, na brincadeira, há uma suspensão das formas de encontro cotidiano. Nesse momento, preponderam as figuras das personagens incorporadas. Julgo que a relação entre colegas não é anulada, e até afeta o desdobramento do jogo. Porém, predomina a experimentação de ser o outro. Assim, Tina e Carla não agem como as meninas e colegas que são; agem como outras pessoas.

As duas meninas criam uma seqüência imaginária em que quase tudo gira em torno das conversas de Tina ao telefone. Os diálogos dessa situação permitem identificar quatro tipos de personagens na história criada: a mãe e a babá, que são parceiras presentes, além da monitora que se insere como participante; a filha, representada pela boneca, à qual Tina se refere como "a nenê"; o interlocutor do telefone (companheiro de Tina); e, ainda, uma pessoa mencionada por Tina como a namorada, 
uma rival. Ou seja, os enunciados não só configuram as personagens na cena percebida (pessoas, boneca) mas também aqueles apenas presumidos, criados pelas palavras (o companheiro, a namorada).

Há, pois, vários outros que ganham vida no plano imaginário. Ademais, as crianças, ao experimentarem um "eu fictício", desempenham ações e têm posturas diferenciadas frente a cada um dos demais personagens. Por exemplo, focalizando Tina, nota-se que ela se coloca diferentemente em relação à babá, à filha, ao companheiro e assim por diante. Dessa forma, no brincar, as crianças orquestram uma rede de relações e de personagens que refletem e reelaboram a experiência cultural.

O jogo com personagens incorporados, como o de Tina e Carla, tem algumas características distintas daquele que envolve personagens projetados. Esse segundo caso diz respeito a situações em que as crianças manuseiam figuras-personagens (em geral miniaturas de animais ou bonecos) e relatam os acontecimentos que vão imaginando. Tipicamente, o participante não fala como personagem, mas, com seus enunciados, atribui ações e falas às figuras. Atua mais como narrador, numa necessária articulação com a manipulação de bonecos e objetos (de maneira semeIhante, em alguns aspectos, ao manipulador de fantoches). Diferentemente das circunstâncias em que o personagem é incorporado, aqui a criança não age e fala no plano da encenação. Fica, em certo sentido, num lugar externo a esse plano. $E$ isso traz indicações interessantes adicionais sobre a variedade de relações que os sujeitos estabelecem com os outros, recriados nas encenações. Por exemplo, num jogo com dinossauros, os meninos manipulam as miniaturas, atribuindo-lhes os gêneros de macho e fêmea, e dizendo: Ela caiu. Daí ela levantou de novo. E ela vai tomar mais força! Ele tá lutando com o filho do amarelo etc.

Vê-se, naturalmente, uma tendência a se reportar aos personagens como ele(s) e ela(s), em função do lugar de narrador. Mas, vale notar que as crianças podem assumir posições mescladas, colocando-se às vezes como personagens e alterando o uso de pronomes. Por exemplo, na brincadeira com os dinossauros, aparecem o pronome "eu" e verbos usados na primeira pessoa: Eu não matei meu filho./ Agora ela mordeu eu!/ Joguei ele na praia!

Essas ocorrências mostram que a distinção entre encenações com personagem incorporado e projetado é muito relativa; em diferentes brincadeiras, essas modalidades podem ocorrer de forma exclusiva, alternada ou mesclada. Personagens incorporados podem se deslocar para a 
posição de narrador dos acontecimentos da encenação ou, o que é especialmente curioso, de narrador de suas próprias ações. Por exemplo, numa brincadeira de polícia-ladrão, a mesma criança que age e fala como ladrão, a certa altura começa a narrar, antecipando ou acompanhando suas ações: Aí eu roubava um monte de jóias/ Daí eu entortei sua arma e corteil Aí eu roubava o telefoninho etc. É como se o personagem se desdobrasse (em pelo menos dois "eus fictícios"), já que ele narra mas continua sendo, atuando e falando como ladrão.

Dessa maneira, as crianças mostram uma mobilidade e uma versatilidade na criação do jogo, experimentando os lugares dos outros da cultura, elaborando sobre suas imagens. "Eus" e "outros" se misturam e se distinguem no jogo. Os modelos sociais, ao mesmo tempo que se impõem como típicos, não são congelados. Ao vivenciar essas relações, o sujeito desdobra-se, divide-se e, como os outros, não é uno ou homogêneo.

É possível sugerir, então, que o brincar de ser e recriar os outros da cultura consiste num intenso trabalho de diferenciação e identificação entre eu e outro; um trabalho em que, naturalmente, a criança não está agindo com esse intuito, de forma deliberada ou reflexiva. E, quanto a esse ponto, cabe um esclarecimento. Não estou propondo que essas instâncias de uso da imaginação têm o mesmo caráter da encenação artística ou, mais amplamente, das produções estéticas do adulto (que podem ser objeto de discussão semelhante, porém de outra perspectiva). Não se trata dos mesmos processos. Bakhtin (1997) aponta a diferença entre os dois casos, dizendo que a arte se distingue, por requerer as figuras de espectador e de autor. Em relação às brincadeiras infantis encenadas, o autor afirma:

O garoto que representa o chefe dos bandidos vive sua vida de bandido por dentro: é pelos olhos do bandido que ele vê um segundo garoto passar correndo na frente de um terceiro garoto que, por sua vez, é o viajante. Seu horizonte é o horizonte do bandido representado. O mesmo acontece também com seus companheiros de representação. A relação mantida por cada um deles com 0 acontecimento da vida que decidiram representar -0 ataque à diligência - nada mais é senão o desejo de tomar parte do acontecimento, o desejo de viver essa vida na qualidade de participante: um quererá ser o bandido, outro o viajante, outro ainda o policial, etc. Essa relação com a vida que se manifesta no desejo de vivêla em pessoa não é uma relação estética com a vida. (p. 90) 
Os comentários analíticos que apresentei sobre o jogo imaginário são muito tímidos diante da complexidade do tema abordado. Entretanto, eles permitem sugerir que as instâncias de funcionamento da imaginação podem ser de especial interesse para expandir, na abordagem históricocultural, a discussão sobre as relações sociais, sobretudo porque põem à mostra a necessidade de se examinar as noções do eu e do outro como construção que implica imagens múltiplas e a necessidade de se reconhecer que essas noções são também da ordem da imaginação, que deve ser articulada às dimensões cognitivas e afetivas dos processos em foco.

\section{Considerações finais}

As proposições de Vigotski, em vários de seus trabalhos e no "Manuscrito", são ainda hoje muito profícuas para guiar análises sobre as relações eu-outro e para alertar quanto a riscos de simplificação desse amplo tema. Das linhas e entrelinhas do "Manuscrito", parece-me que podem ser derivados certos alertas que correspondem a cuidados conceituais e metodológicos, nem sempre fáceis de atender. Se o eu e o outro são noções que têm um caráter concreto e não devem ser tomadas como abstrações, e se a relação eu-outro diz respeito a acontecimentos reais, mas não se reduz a instâncias meramente empíricas, então colocamse algumas conseqüências: o estudo das relações sociais não pode restringir-se ao exame do plano observável das interações face a face; os processos de linguagem que acontecem nessas interações devem ser vistos como algo mais do que a conversação de interlocutores imediatos; os efeitos dos outros sobre o indivíduo não dependem somente de formas de atuação direta; os outros não são apenas as pessoas fisicamente presentes, mas também "figuras-tipo" da cultura ou representantes dos códigos e normas, participantes das práticas sociais. Esses pontos correspondem a uma parte dos riscos mencionados.

Por outro lado, o mesmo conjunto de proposições não oferece explicitações suficientes para esses cuidados e aprofundamentos. Certamente, não é um problema exclusivo da visão teórica em foco. Mas, ao ler - "Manuscrito" (naquilo que mais concerne a ao presente texto), nota-se um emaranhado de conceitos, sendo alguns razoavelmente distintos e outros aparentemente superpostos - indivíduo, homem, pessoa, personalidade, personalidade social, mim, eu, outro, socius etc. E, no que concerne aos significados desses termos, também existem sutilezas decorrentes de diferen- 
ças entre os contextos de debates teóricos do início do século e dos dias de hoje. Ainda assim, chama a atenção o entrelaçamento difícil daqueles conceitos em anotações como "O homem é uma pessoa social = um agregado de relações sociais incorporadas num indivíduo" (p. 66, itálico do autor; sublinhado meu). Não se deve esquecer que esse tipo de enunciado reflete o caráter de um esboço de idéias para si, mas várias dúvidas permanecem quando se transita desse para outros textos de Vigotski.

Sintetizando estas últimas considerações, quero indicar que a contribuição de Vigotski para os temas aqui discutidos pode ser caracterizada a partir de, pelo menos, dois ângulos: o primeiro abrange teses formuladas ou análises e afirmações mais consistentes; o segundo compõe-se daquilo que é sugerido, esboçado, anunciado, deixando questões em aberto. $O$ dois ângulos dão pistas para o enfrentamento de desafios contínuos. Creio que este é, de maneira geral, o valor da leitura que fazemos de pensadores importantes, cuja produção precede o panorama das discussões que nos ocupam na atualidade.

\section{Notas}

1. Nas menções de trabalhos no corpo do texto, $\mathrm{o}$ ano corresponde à edição consultada. Dependendo das informações disponíveis, as datas das publicações originais estão indicadas na Bibliografia.

2. Para facilitar, esse texto de Vigotski será referido como "Manuscrito".

3. Cabe esclarecer que os tradutores da revista que publicou a versão em inglês do "Manuscrito" não puderam identificar o trabalho de Janet que estaria relacionado às menções feitas por Vigotski (conforme Nota 5 da publicação). Um dos livros que focalizo foi editado em 1929 - L'Evolutión psychologique de la personnalité. Nele, há discussões que correspondem a vários destaques feitos no "Manuscrito". Assim, considerada a data de publicação, é possível, mas incerto, que essa obra tenha sido uma das fontes envolvidas. Ao mesmo tempo, apesar de não ser uma publicação contemporânea a Vigotski, julguei pertinente reportar-me a um texto de Janet de 1936, L'intelligence avant le langage, no qual são reiteradas e desdobradas as proposições de 1929 e de trabalhos anteriores. As referências que faço a esses livros são bastante seletivas, restringindo-se a pontos de maior relevância para esta discussão.

4. Aqui estou me referindo às possibilidades de ampliação desse tema na perspectiva histórico-cultural, possibilidades que têm sido melhor exploradas, parece-me, nas vertentes dessa perspectiva que privilegiam as práticas sociais e discursivas. Naturalmente, cabe reconhecer que essa discussão 
se faz presente em vários campos e correntes teóricas, com diferentes níveis de adensamento e sistematização conceitual. Vinculada à visão sociogenética, é importante lembrar a teorização de Henri Wallon a esse respeito. Zazzo (1978) aborda as valiosas contribuições desse autor sobre "o problema do outro" na Psicologia, lembrando influências de P. Janet e apontando diferentes concepções anunciadas por Wallon: os "outros" (das relações interpessoais), o "Outro" (como conceito geral) e o socius (como o outro íntimo).

5. Irei mencionar algumas indicações de um projeto sobre o jogo de faz-de-conta entre crianças, na faixa etária de 3 a 7 anos. Trata-se de um trabalho em andamento, que envolve a filmagem de situações de brincadeira livre de grupos de crianças, numa brinquedoteca de instituição municipal de educação infantil, de uma cidade do interior de São Paulo. O projeto está sendo financiado pela Fapesp.

Encaminhado para publicação em maio de 2000

\title{
The formation of the individual in social relations: theoretical contributions of Lev Vygotsky and Pierre Janet
}

\begin{abstract}
This paper examines the Manuscript "Concrete Human Psychology", by Lev Vygotsky, with the purpose of highlighting the vigour of the author's arguments about the fundamental role of social relations in the individual formation. The focus lies on passages of the text which are more pertinent to the reciprocal construction of the "self" and the "other". In the approach to this theme, some propositions of Pierre Janet are explored, since he is one of the most important references (the) Vygotsky includes in the Manuscript. Next, the contributions of these self and the other, in the imaginary play of children. Finally, the proficuous perspectives for investigation offered by the Manuscript are remarked, as well as the complex issues that it leaves unclosed.
\end{abstract}

\section{Bibliografia}

Bakhtin, M. Estética da criação verbal. São Paulo: Martins Fontes, $2^{3}$ ed., 1997 [composto de textos originais de diferentes datas].

Janet, P. L'évolution psychologique de la personnalité. Paris: Ed. A. Chahine, 1929. 
L'intelligence avant le langage. Paris: E. Flammarion.

Vygotsky, L.S. The genesis of higher mental functions. In J.V. Wertsch (Org.) The concept of activity in Soviet Psychology. Nova lorque: M.E. Sharpe, 1981 [original de 1931]. A formação social da mente. São Paulo: Martins Fontes, 1984 [org. M. Cole e outros - textos originais de diferentes datas]. . (1934/1987) Problems of General Psychology - The Collected Works of L.S. Vigotski - volume 1. Nova lorque: Plenum Press, 1987a [original de 19340.

. Imaginación y el arte en la infancia. Cidade do México: Hispanicas, 1987b [original de 1930]. . "Concrete Human Psychology", in Soviet Psychology, 27(2) pp. 53-77. [publicação original 1986; escrito em 1929].

Zazzo, R. Henri Wallon - Psicologia e Marxismo. Lisboa: Ed. Vega, 1978. 